\title{
(t)
}

X. (2) (a)

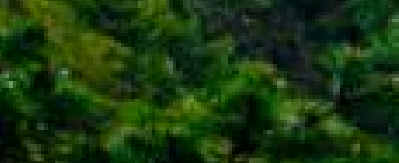
atests

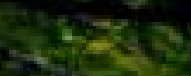

tots $-1,5$

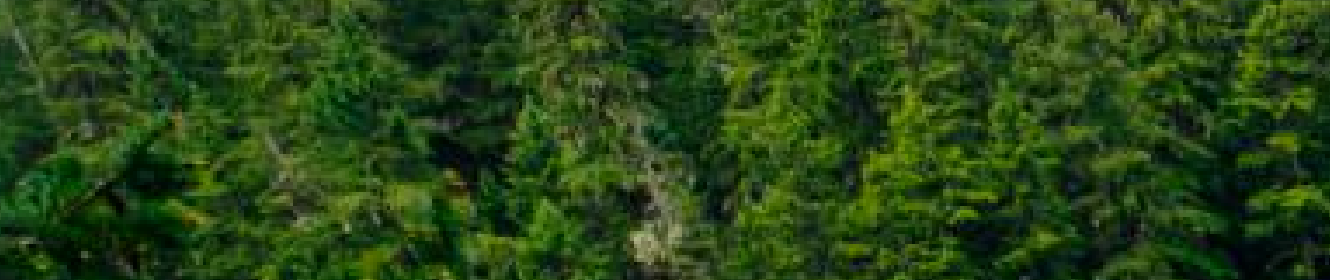
$x+\frac{1}{2}$ 2. W.

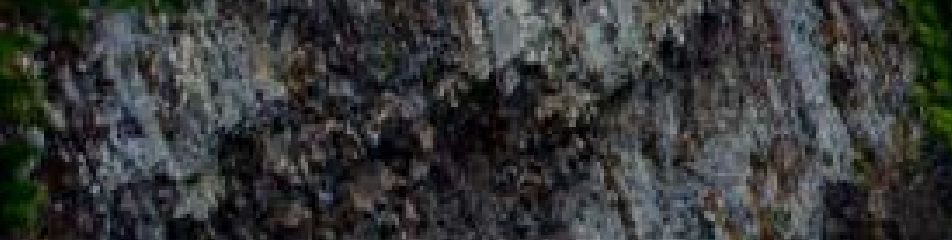

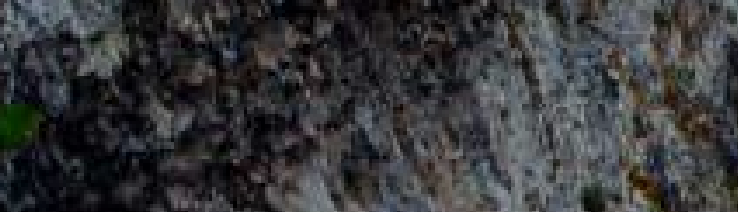

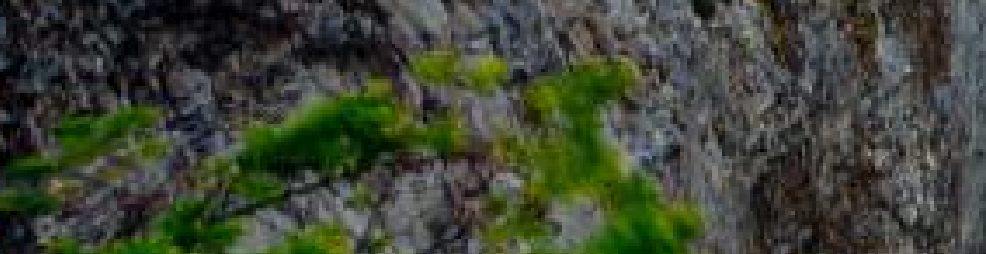
Q.

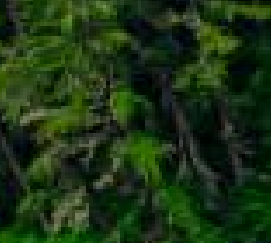

-

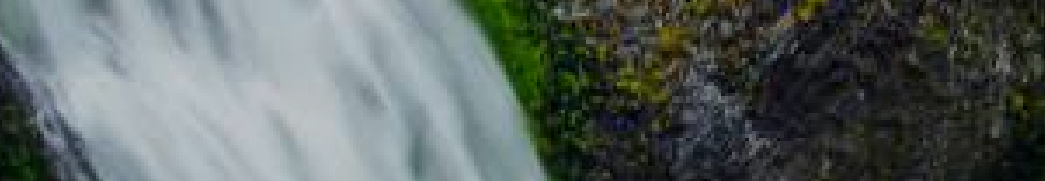




\section{¿Existe el derecho al desarrollo sostenible?}

El concepto de desarrollo sostenible surge a partir del documento Nuestro futuro común, más conocido como Informe Brundtland, publicado por la Comisión sobre Medio Ambiente y Desarrollo de la Organización de lasNaciones Unidas (ONU) entre 1982 y 1983.

Por Cecilia Quiroz Pacheco 


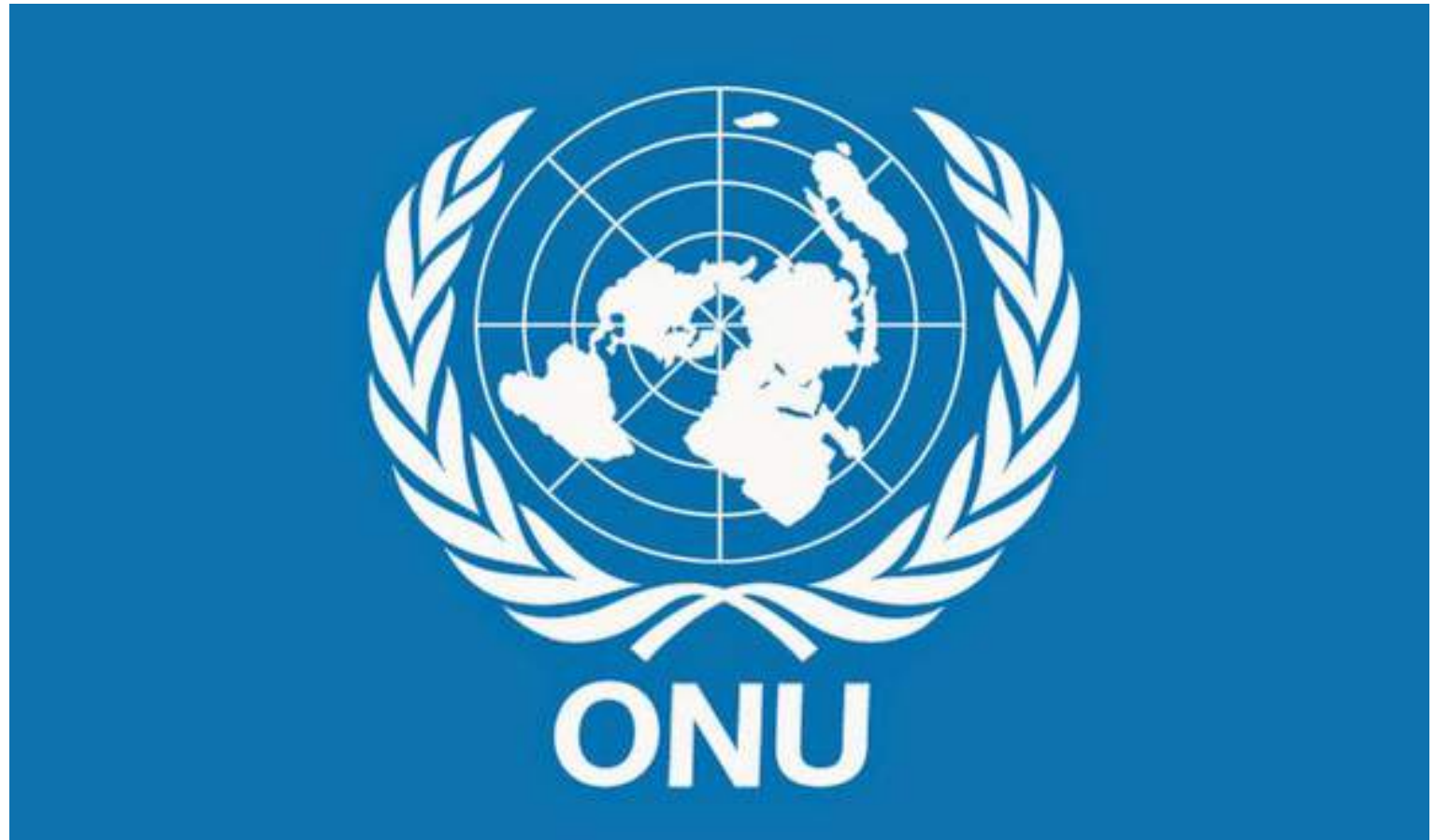

se está imponiendo un paradigma de sociedad del futuro sobre la base de un modelo ultraliberal junto con sus valores e intereses (neoliberalismo de mercado); este margina lo humano, social y cultural frente a la preponderancia de lo económico, financiero y comercial. En este contexto, ¿es factible la existencia del derecho al desarrollo sostenible?

Figura 3. Derecho al medio ambiente

Fuente: ONU

$\mathrm{E}$ visión del modelo de desarrollo que los países industrializados aplican y que se replica en los países de la periferia. Se hace notar que existe incompatibilidad entre los modelos de producción y consumo vigentes, los que están agotando y afectando los recursos naturales y la capacidad de soporte de los ecosistemas. Además, se propone como alternativa la necesidad de un nuevo modelo, el desarrollo sostenible, que implica limitaciones a la sobreexplotación, exige una distribución más equitativa de los recursos y requiere de un gran apoyo político para lograrlo.
En el informe, se propusieron restricciones que involucraron propuestas para no poner en peligro los sistemas que sostienen la vida en el planeta: usar eficientemente los recursos naturales y privilegiar el bienestar humano sin afectar a las generaciones futuras. Es decir, se planteó un modelo duradero en el tiempo, eficiente y racional en el uso de los recursos, y equitativo en los beneficios. Esa es la base del desarrollo sostenible. Sin embargo, en el contexto actual, que se caracteriza por una visión individualista y mercantil de la realidad humana, que tiende a invisibilizar las desigualdades económicas y sociales existentes,$$
\text { . }
$$

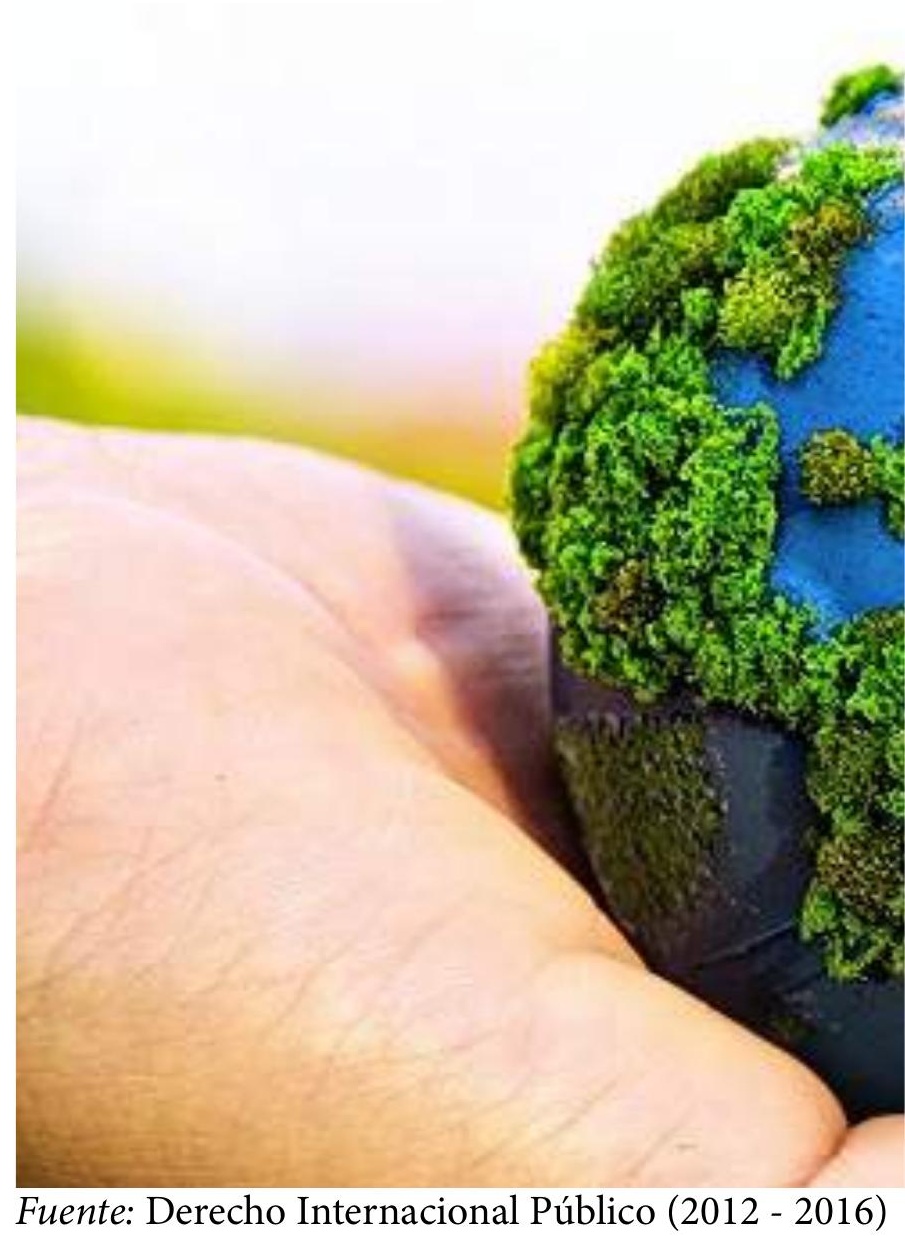

Figura 2. Desarrollo sustentable

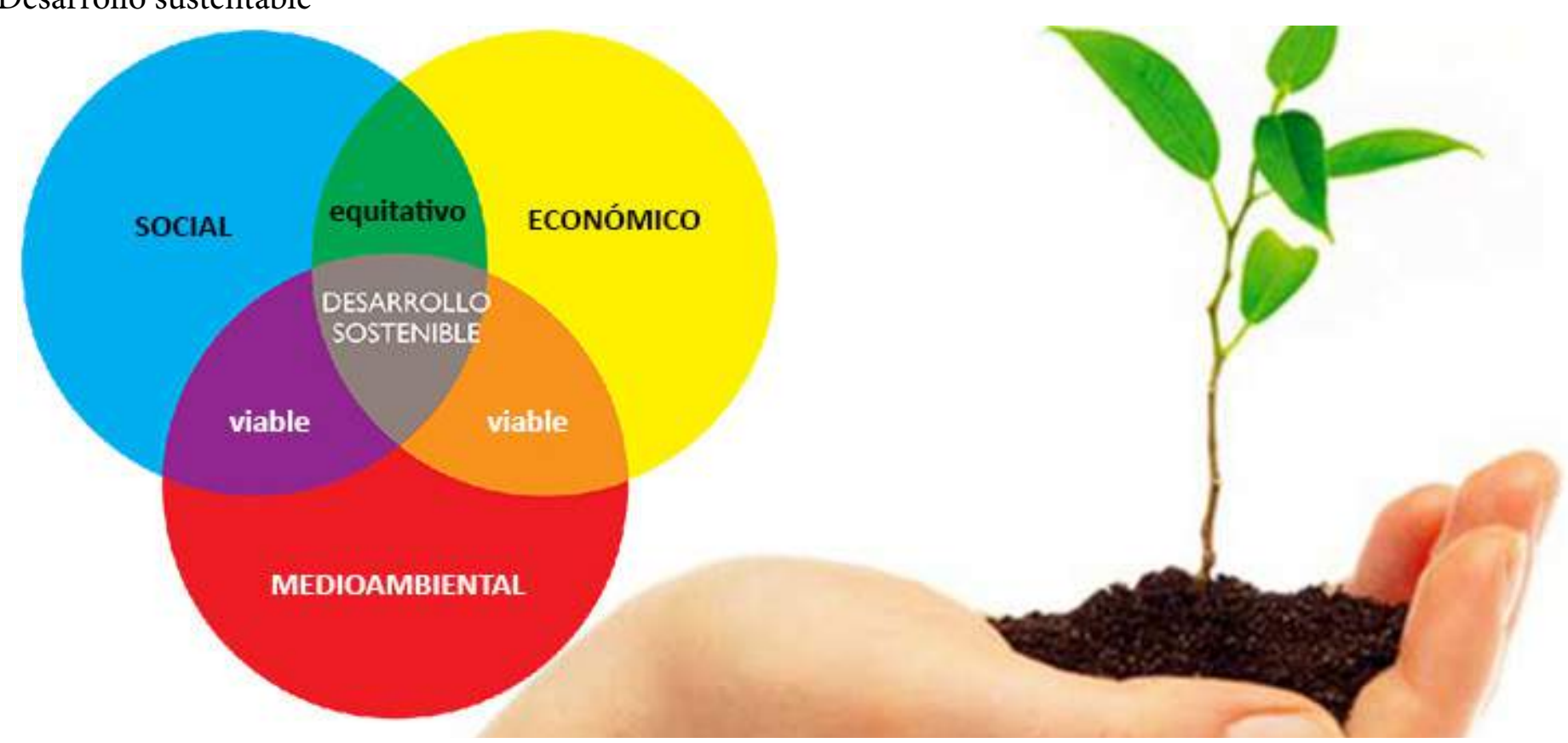

Fuente: Nuestraesfera. Espacio Educativo (2013) 
En tanto las normas garantizan que todo individuo debe estar en condiciones de desarrollar al máximo sus capacidades, sentirse libre y digno de sí mismo, y lograr el máximo bienestar humano, podemos afirmar que el derecho al desarrollo sostenible constituye uno de los derechos humanos, y que está más allá de las políticas regionales o locales que, muchas veces, privilegian
Con arreglo a la Declaración Universal de Derechos Humanos, no puede realizarse el ideal del ser humano libre, en el disfrute de las libertades civiles y políticas y liberado del temor y de la miseria, a menos que se creen condiciones que permitan a cada persona gozar de sus derechos civiles y políticos, tanto como de sus derechos económi-

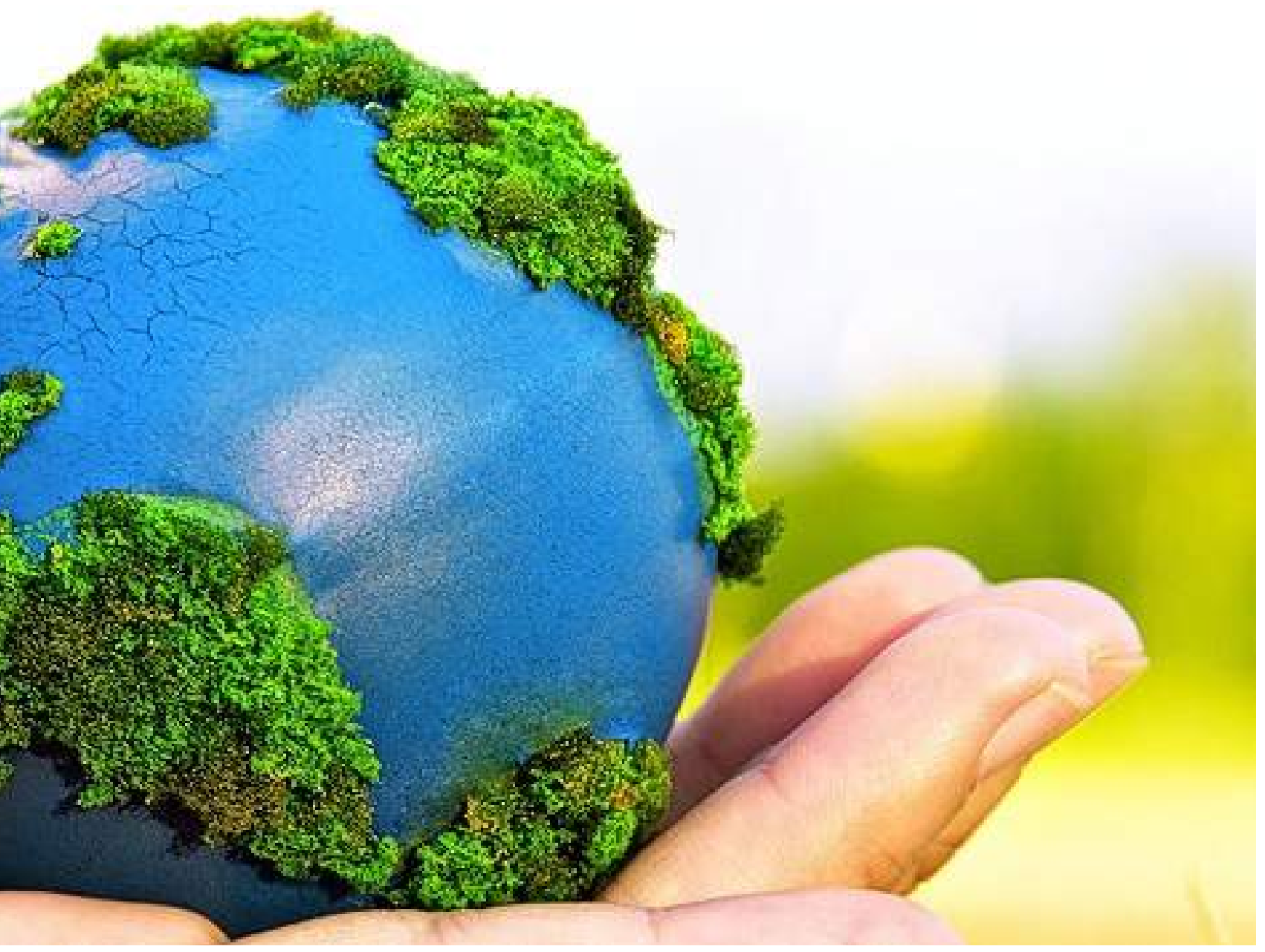

cos, sociales y culturales. . . (Oficina del Alto Comisionado de las Naciones Unidas para los Derechos Humanos, 1976, párr. 1)

Este derecho posee una dimensión tanto individual como colectiva, que se desarrolla sobre la base de textos jurídicos internacionales (softlaw), elaborados, por un lado, por organismos supranacionales, $y$, por el otro, sobre la base de la cultura y la filosofía de los derechos humanos, los derechos fundamentales y los valores con vocación universalista en que se inspiran.

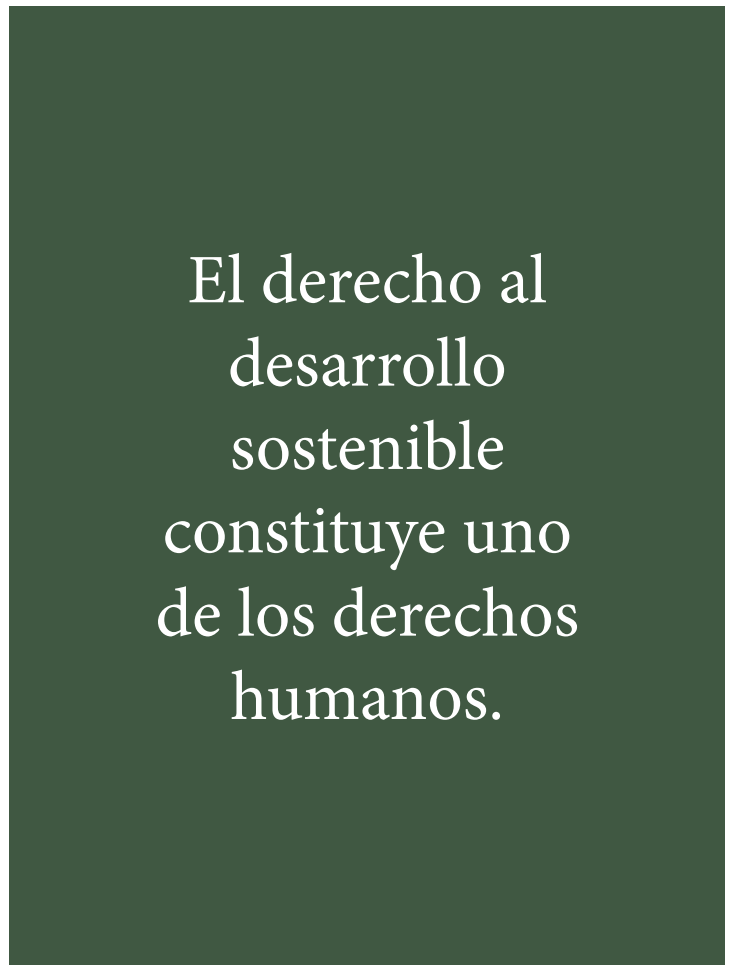

los resultados económicos financieros. En este sentido, el desarrollo sostenible agrupa el conjunto de los derechos humanos, como ha sido manifestado en la Declaración y programa de acción de Viena de 1993 (Oficina del Alto Comisionado de las Naciones Unidas para los Derechos Humanos, 2013), y de acuerdo con lo dispuesto en los preámbulos del Pacto Internacional de los Derechos Económicos, Sociales y Culturales y del Pacto Internacional de los Derechos Civiles y Políticos, adoptados en el marco de la Asamblea General de las Naciones Unidas de 1966:
Figura 4. Hacia el desarrollo sostenible

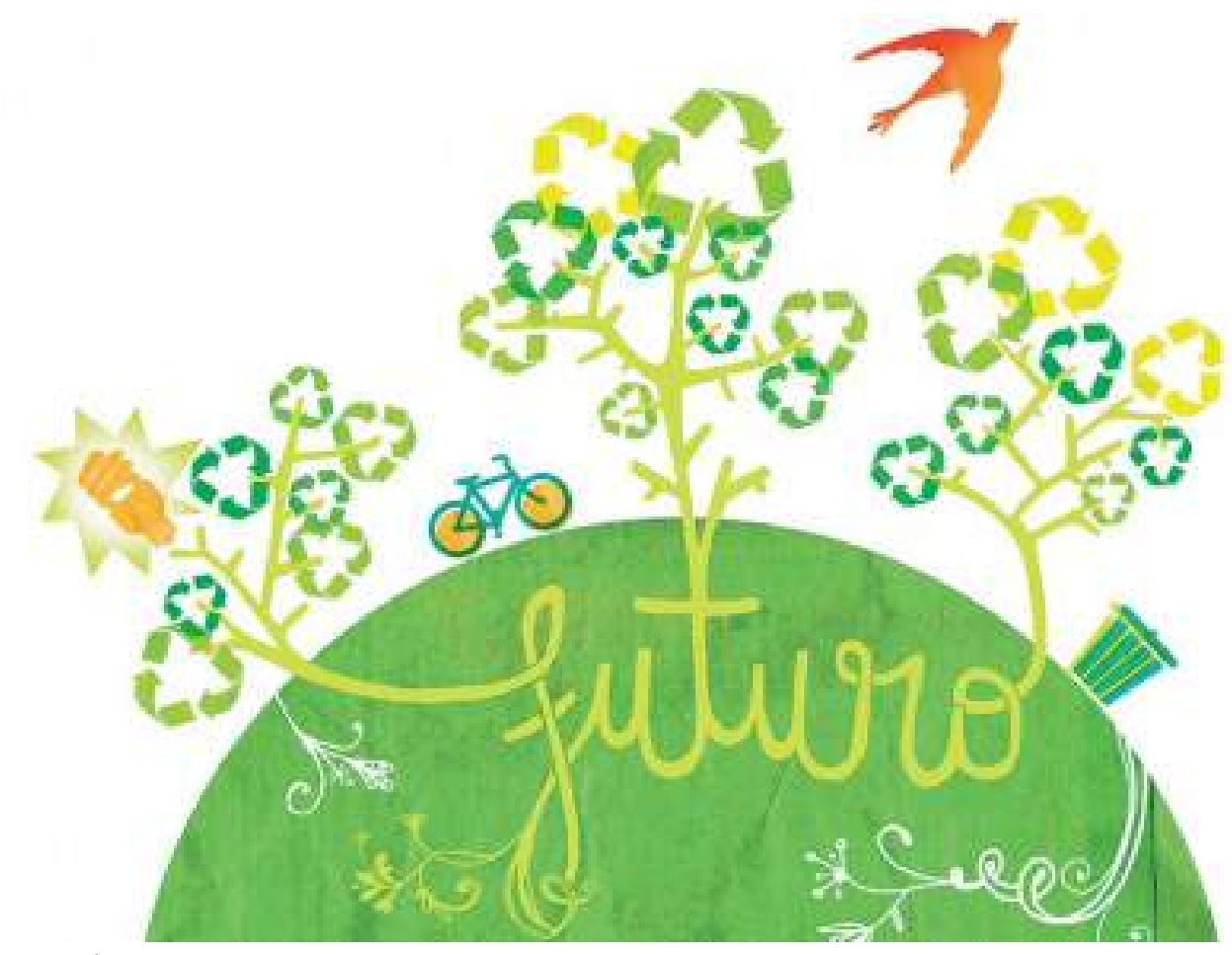

Fuente: Alma Larroca 
El ejercicio del derecho al desarrollo no se basa solo en un crecimiento económico que considere que los beneficios de la actividad económica y comercial deban ser equitativamente repartidos entre todos los individuos y grupos humanos, y que atienda especialmente las necesidades de los individuos y grupos más vulnerables. También debe basarse en la necesidad de implementar políticas redistributivas eficientes y eficaces, que permitan que los beneficios obtenidos de la gestión de los recursos alcancen no solo a las generaciones presentes, sino a las futuras, y que se comprometan con el diseño y ejecución de planes a mediano y largo plazo que respeten la diversidad cultural.

En conclusión, se debe tener claro que, tras la concepción del derecho al desarrollo sostenible como uno de los derechos humanos, se hallan tres aspectos. El primero es la aspiración a que la libertad y la dignidad estén al alcance de todos los seres humanos. El segundo es que sea realizable, es decir, que se creen las condiciones para que todos puedan satisfacer sus necesidades legítimas, y realizar sus proyectos o planes de vida igualmente legítimos. El tercero es que se considere como beneficiarias no solo a las generaciones presentes, sino también a las futuras. 